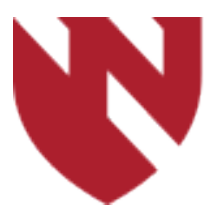

October 2021

\title{
The Advantages of a Rural Resident Rotation in Otolaryngology Training: Comparing Surgical Case Volumes of a Rural Rotation with a University Rotation
}

\author{
Mark Miller \\ University of Nebraska Medical Center \\ Paul J. Brosnihan \\ Vanderbilt University \\ Christie Barnes \\ University of Nebraska Medical Center \\ Jayme Dowdall \\ University of Nebraska Medical Center
}

Tell us how you used this information in this short survey.

Follow this and additional works at: https://digitalcommons.unmc.edu/gmerj

Part of the Higher Education Commons, and the Otolaryngology Commons

\section{Recommended Citation}

Miller, M, Broshnihan, P, Barnes, C, Dowdall, J. The Advantages of a Rural Resident Rotation in Otolaryngology Training: Comparing Surgical Case Volumes of a Rural Rotation with a University Rotation.

This Original Report is brought to you for free and open access by DigitalCommons@UNMC. It has been accepted for inclusion in Graduate Medical Education Research Journal by an authorized editor of DigitalCommons@UNMC. For more information, please contact digitalcommons@unmc.edu. 


\title{
The Advantages of a Rural Resident Rotation in Otolaryngology Training: Comparing Surgical Case Volumes of a Rural Rotation with a University Rotation
}

\author{
Abstract \\ Objective: Rural residency rotations have played a significant role in encouraging surgical residents to \\ pursue a career in a rural community. This study reviews the resident caseload of an otolaryngology \\ residency rural rotation in comparison with a traditional primary university-based urban location. \\ Methods: The Accreditation Council for Graduate Medical Education (ACGME) case log system was used \\ to review cases logged by residents during their rural rotations from July 2017 to December 2018. Case \\ log data were compared with a matched resident of similar training experience on the university service \\ during the same time period.
}

Results: Rural residents reported more cases than their urban-based counterparts (1143 vs 690 cases). Junior residents had over double the number of cases in rural practice (400) compared to junior residents on the university service (168). The university service was much stronger on H\&N Neck (54 vs. 28 cases), Larynx (39 vs 8 ) and Endoscopy (92 vs 42). In contrast, the rural rotation provided substantially more Endocrine cases (103 vs 47 ) and comparable Salivary cases (23 vs 21 ) compared to the university service.

Discussion: This study defines a surgically robust rotation in rural medicine and highlights the possibility of obtaining exposure to a surgical practice unique to a rural setting. By participating in high volume surgical rural residency rotations, trainees may better understand the otolaryngologic needs of a rural

\section{Keywords}

Rural, Residency, Otolaryngology, Surgery, Case Volume, Patient Safety, Quality Improvement, Graduate Medical Education

\section{Creative Commons License}

\section{(c) $(1)(9)$}

This work is licensed under a Creative Commons Attribution-Noncommercial-No Derivative Works 4.0 License. 


\section{The Advantages of a Rural Rotation in Otolaryngology Residency Training: Comparing Surgical Case Volumes of a Rural Rotation with a University Rotation}

Mark Miller $^{1}$, Paul J. Brosnihan², Christie Barnes ${ }^{1}$, Jayme Dowdall ${ }^{1}$

${ }^{1}$ University of Nebraska Medical Center, College of Medicine, Department of Otolaryngology - Head and Neck Surgery

${ }^{2}$ Vanderbilt University

https://doi.org/10.32873/unmc.dc.gmerj.3.1.006

\begin{abstract}
Introduction: Rural residency rotations have played a significant role in encouraging surgical residents to pursue a career in a rural community. This study reviews the resident caseload of an otolaryngology residency rural rotation in comparison with a traditional primary university-based urban location.
\end{abstract}

Methods: The Accreditation Council for Graduate Medical Education (ACGME) case log system was used to review cases logged by residents during their rural rotations from July 2017 to December 2018. Case log data were compared with a matched resident of similar training experience on the university service during the same time period.

Results: Rural residents reported more cases than their urban-based counterparts (1143 vs 690 cases). Junior residents had over double the number of cases in rural practice (400) compared to junior residents on the university service (168). The university service was much stronger on head and neck (54 vs. 28 cases), larynx (39 vs 8), and endoscopy (92 vs 42 ). In contrast, the rural rotation provided substantially more endocrine cases (103 vs 47 ) and comparable salivary cases ( 23 vs 21 ) compared to the university service.

Conclusion: This study defines a surgically robust rotation in rural medicine and highlights the possibility of obtaining exposure to a surgical practice unique to a rural setting. By participating in high volume surgical rural residency rotations, trainees may better understand the otolaryngologic needs of a rural community.

\section{Introduction}

Despite a growing need for rural providers, Otolaryngology - Head and Neck Surgery (OHNS) surgeon coverage is trending toward urban consolidation. ${ }^{1}$ Challenges to rural surgery include professional isolation, lack of call coverage, and physician reimbursement. ${ }^{2}$

The decision to pursue a rural practice is multifactorial. While growing up in a rural environment may be the strongest predictor of practice in a rural setting, other factors exist. ${ }^{2}$ Exposure to rural curriculum in medical school increases the likelihood of choosing an internship in a rural hospital. ${ }^{3}$

Rural residency rotations have been cited as a significant factor in retention of family practitioners and surgical residents alike. ${ }^{2} \mathrm{~A}$ recent study reviewed all accredited general surgery programs and showed that only 27 out of 268 surgical residency programs had provided the opportunity for rural rotations. ${ }^{4}$ Among general surgery residents exposed to rural rotations, residents who completed rural rotations were more likely to enter a general surgery practice in a location with a population less than 50,000 . $^{5}$

Unfortunately, similar data are not available for OHNS training programs, and the benefits of a rural residency rotation in our specialty have not been well described. In 2016, the University of Nebraska Department of Otolaryngology - Head and Neck Surgery established a rural residency rotation with one of its former residents working in rural private practice. Each resident spends two months on the rural residency service as a junior resident (year two or three), and two months as a senior resident (year four or five).

The rural rotation occurs in a private practice with two full-time operating attending physicians; one of whom is a graduate of University of Nebraska Medical Center (UNMC) Department of Otolaryngology residency program. The practice resides in a town of approximately 34,000 people with two hospitals. Operations occur at a Level II trauma center with $>200$ beds and at a private ambulatory care center. The two physicians take full facial trauma call at the trauma center, and no oral surgery or plastic surgery attendings share call in the area.

In comparison, the primary medical center rotation is an academic practice with nine faculty, including sub-specialist representation in rhinology, facial plastic surgery, head and neck surgery, laryngology, pediatric otolaryngology, neurotology, and general otolaryngology. The academic service shares trauma call with Oromaxillofacial Surgery (OMFS) and Plastic Surgery.

In order to ensure that the rural residency experience aligns with department and residency program objectives, this study reviews the resident caseload of the rural rotation and compares it with a traditional urban-based rotation at the primary university medical center. We hypothesize that the rural residency rotation provides a comparable surgical caseload volume while providing a unique blend of surgical experiences that differentiates it as a valuable part of the OHNS residency curriculum.

\section{Methods}

The Accreditation Council for Graduate Medical Education (ACGME) case log system is utilized by all OHNS residency programs to monitor and track resident cases. We extracted and reviewed all cases from residents participating in the rural resident rotation from July 2017 to December 2018. Case log data were also extracted and reviewed for a matched resident of similar training experience at the university-based general ENT service during the same time period. The general ENT service covers all of the subspecialty services of the OHNS Department.

For example, when a post-graduate year 5 (PGY-5) resident was on the rural rotation, the caseload of the PGY-5 resident on the university service at the same time was reviewed. Where years of training did not match perfectly, junior residents (PGY2 \& 3 ) were compared with junior residents, and senior residents (PGY4 \& 5) with senior residents (Table 1).

Data were reviewed in aggregate as well as categorically as organized by the ACGME case log system. The Residency Review Committee for OHNS designates minimal standards for graduation, including minimum numbers of "key indicator" cases. These key indicator cases were also reviewed apart from the aggregate data. This study was deemed IRB exempt and the ACGME approved usage of these data.

\section{Results}

From July 2017 to December 2018, nine residents at UNMC rotated on the rural rotation and reported their surgical cases 
Table 1.

Pairing of residents by PGY year and location distributed by month from 2017-2018.

\begin{tabular}{lcccccccccccc}
2017 & JAN & FEB & MAR & APR & MAY & JUN & JUL & AUG & SEP & OCT & NOV & DEC \\
\hline Rural Resident & & & & & & & PGY5 & PGY5 & PGY3 & PGY3 & PGY5 & PGY5 \\
\hline University Resident & & & & & & & PGY5 & PGY5 & PGY2 & PGY2 & PGY5 & PGY5 \\
2018 & JAN & FEB & MAR & APR & MAY & JUN & JUL & AUG & SEP & OCT & NOV & DEC \\
\hline Rural Resident & PGY5 & PGY5 & PGY4 & PGY4 & PGY5 & PGY5 & PGY4 & PGY4 & PGY3 & PGY3 & PGY3 & PGY3 \\
\hline University Resident & PGY5 & PGY5 & PGY4 & PGY4 & PGY5 & PGY5 & PGY3 & PGY3 & PGY4 & PGY4 & PGY3 & PGY3 \\
\hline
\end{tabular}

in the ACGME case log system. Residents were matched with another resident on the university service who was a similar experience level based on post-graduate year (PGY); junior residents (PGY2 \& 3) with junior residents, senior (PGY4 \& 5) with senior residents (Table 1).

Over the 18 months that data were collected, the residents reported a total of 1833 cases at the combined rotation locations. The rural service accounted for $62 \%$ of these cases or 1143 cases in total. The university service accounted for $38 \%$ of the total cases or 690 cases in total.

When analyzing the breakdown of the total cases by surgery case type, trends appeared that differentiated the two services. The rural service was particularly strong in nose/sinus cases (306), plastics/trauma cases (272), otology/audiology cases (141), and head and neck endocrine cases (103). The university service had the largest caseload in nose/sinus cases (287), gen/peds endoscopy procedures (92), and head and neck - neck dissection cases (54) (Fig. 1).

When looking at total head and neck cases specifically, the two services showed differences in the neck dissections (54 vs. 28) and laryngeal cases (39 vs 8 ) compared to the rural service. The rural service was much stronger with endocrine cases (103 vs 47) compared to the university service (Fig. 1).

The resident logged key indicator cases display similar trends in comparison to the total logged cases. The rural service had a large number of cases in plastics/trauma (133), gen/peds nose/sinus cases (87), and head and neck endocrine cases (100). However, the total common otology/audiology cases in rural practice did not contribute substantially to the resident logged key indicator cases. (27) The university service had the largest number of cases in gen/peds nose/sinus (72), gen/peds endoscopy (65), and head and neck - neck dissection (44) which mirrors the total number of cases (Fig. 2).

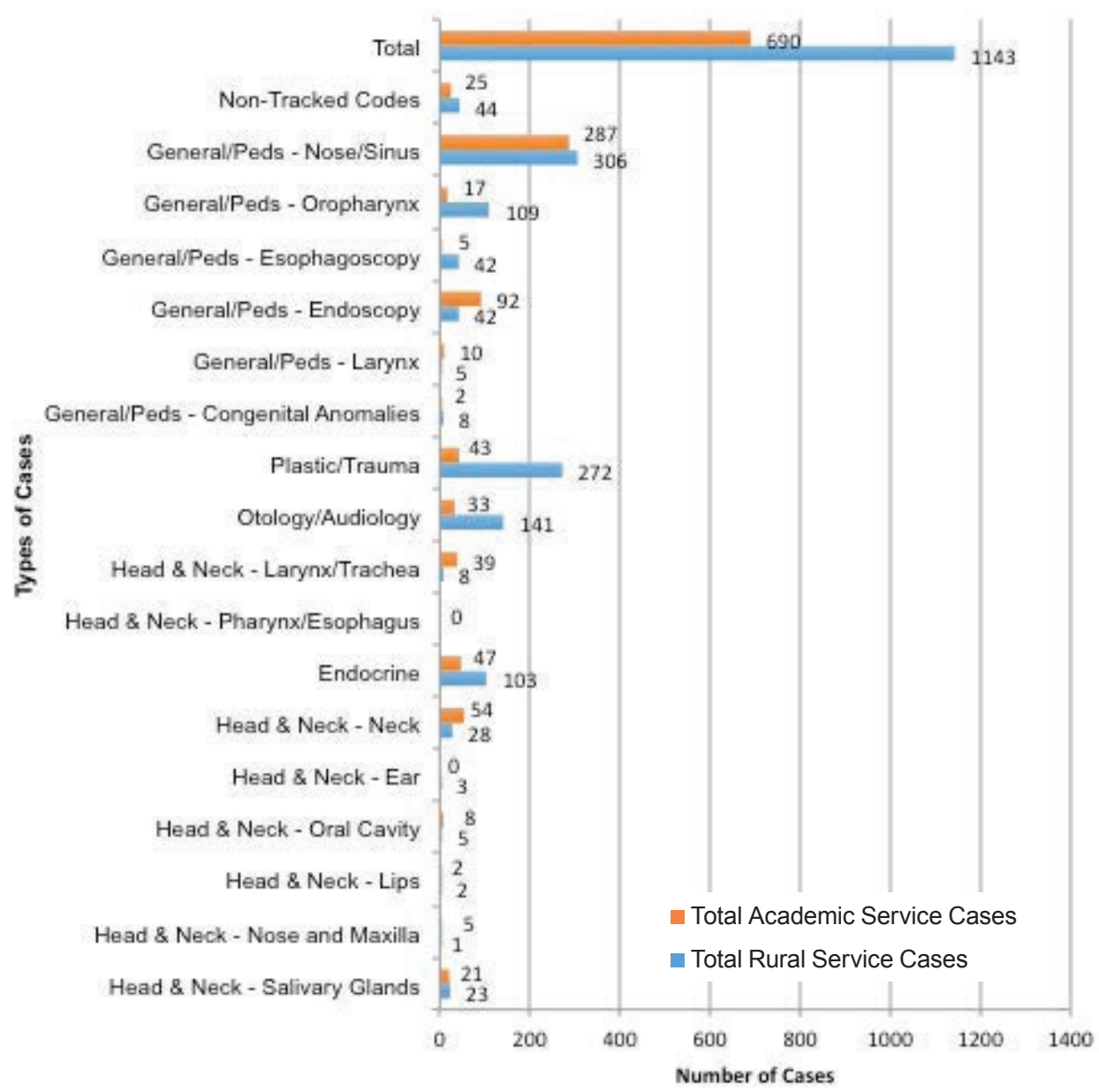

Figure 1. Difference in resident-logged total surgical case volume by location: In total volume of cases, the rural practice had the largest caseload in Gen/Peds Nose/Sinus (306), Plastics/Trauma (272), Otology/Audiology (141), and Head and Neck Endocrine (103). The university service had the largest caseload in Gen/Peds Nose/Sinus (287), Gen/Peds Endoscopy (92), and Head and Neck - Neck Dissection (54).

The total resident-logged case volume was separated by PGY level (junior vs senior) and by location (rural service vs university service). Senior PGYs on the rural service had more cases (743) overall compared to Junior PGYs (400). Senior PGYs had more cases on the rural practice (743) than at the university practice (522). Junior PGYs were able to double the total number of cases during their rural service (400) compared to their university service (168) (Fig. 3).

\section{Discussion}

The urbanization of medicine presents challenges to rural health care, and efforts are being made both in primary care and surgery residencies to address the growing disparities. Providing surgical trainees with exposure to rural medicine through rural rotations may be one way to engage young physicians to pursue careers in rural areas. ${ }^{2}$ This approach has been well described in other surgical specialties but has not been previously described in the field of Otolaryngology - Head and Neck Surgery. 
This study describes the experience of a rural residency rotation at one academic institution. In order to demonstrate feasibility and value of the rural rotation, this study reviews and describes the case volumes of rural residents in comparison with a matched resident on a university-based general ENT service.

Rural resident case volumes exceeded the university resident case volumes when reviewed in aggregate. Key indicator case volumes of rural residents also exceeded the university resident case volumes, although these numbers were more similar.

Caseloads also appeared to differ by type of surgery. The rural rotation provided significantly more exposure to plastics/trauma, otology, general/peds - oropharynx, and head and neck - endocrine cases. In contrast, the university rotation provided more exposure to general/peds - endoscopy, and head and neck - neck cases.

One of the key limitations of this study is the variability in reporting practices by individual residents. While some residents may report all cases, including non-tracked

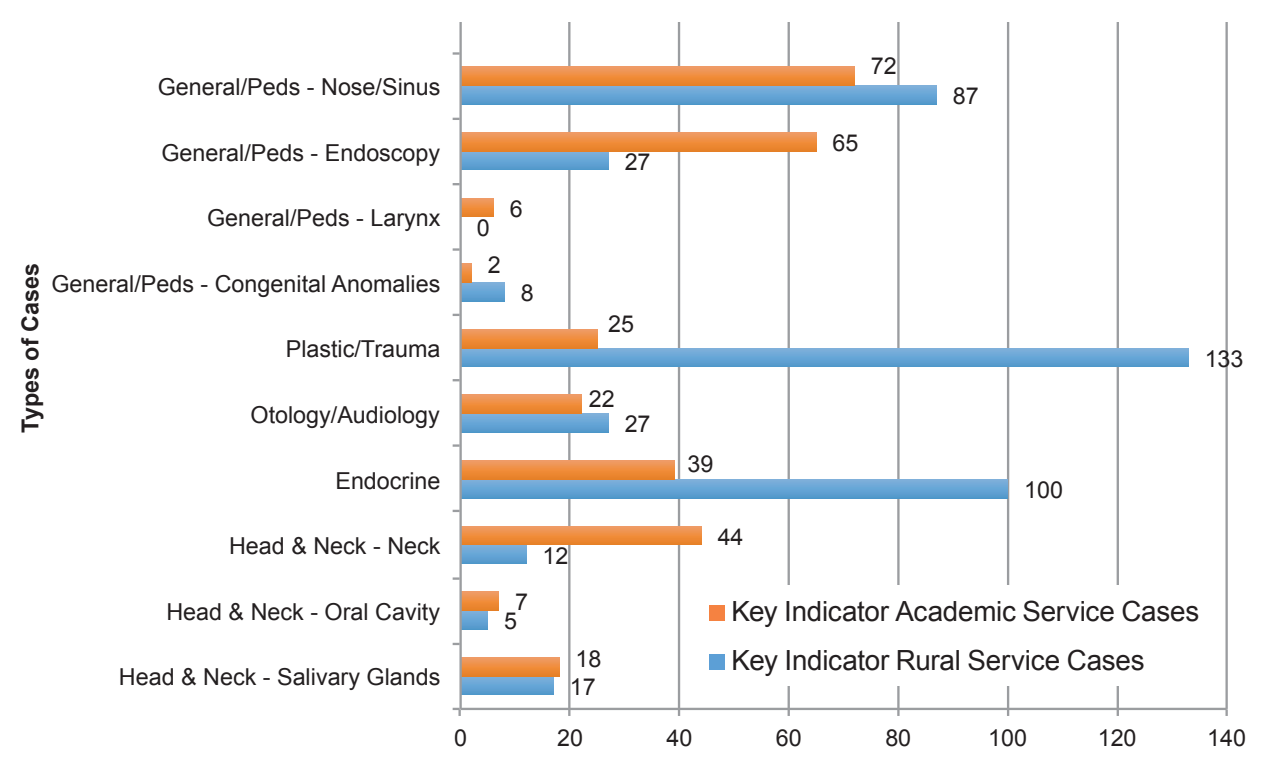

Figure 2. Difference in resident logged key indicator cases by location (2017-2019): The rural service had the largest caseload in Plastics/Trauma (133), Gen/Peds Nose/Sinus (87), and Head and Neck Endocrine (100). The university service had the largest caseload in Gen/Peds Nose/Sinus (72), Gen/ Peds Endoscopy (65), and Head and Neck - Neck Dissection (44).

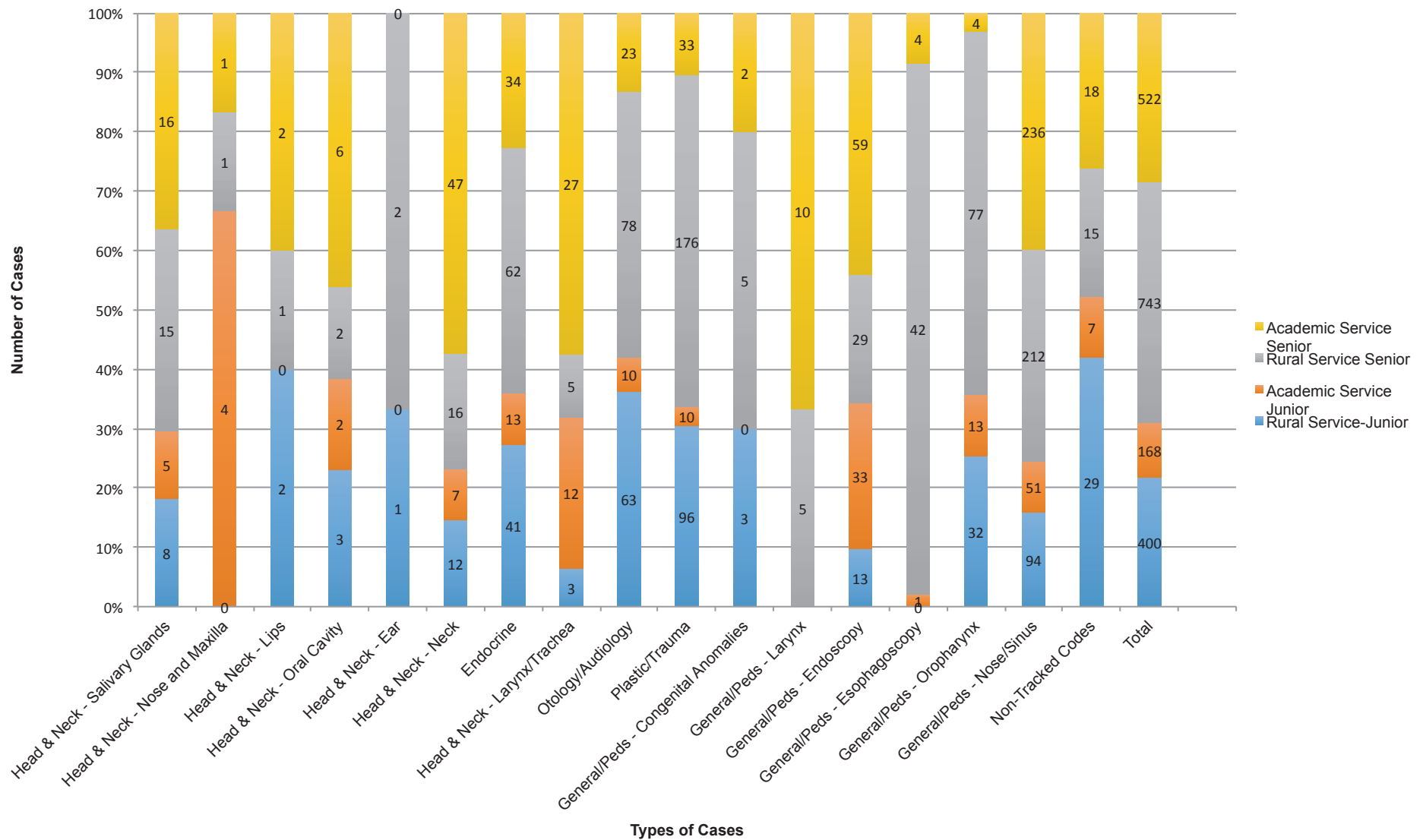

Figure 3. Total resident-logged surgical case volume distribution by location and PGY year (2017-2019): Senior PGYs on the rural service had more cases (743) compared to Junior PGYs (200). Both Senior and Junior PGYs had more cases on the rural practice (743 \& 400) than at the university practice (522 \&168). Junior PGYs were able to double the total number of cases during their service. 
codes and common procedures such as codes for tonsillectomy and adenoidectomy, other residents may stop recording common procedures, or may record cases selectively. We expected this variability in reporting and anticipated that all residents would more carefully record key indicator cases, which have minimal requirements for graduation. While comparison of key indicator cases still demonstrates a robust rural surgical experience, it is possible that selective reporting may add bias to the data. The complexity of the cases available on each rotation is not reported in this study.

The data presented also represent only a brief window of time for this residency program. The addition and subtraction of faculty in an academic institution is common, as is the restructuring of different residency rotations. As such, the amount of exposure to certain surgical procedures may not be easily replicated given these fluctuations.

The complexity of surgical cases at a university service may account for some of the relative decrease in volume when compared to the rural rotation. The larger proportion of neck dissections and laryngology procedures in the academic rotation do show a higher level of complexity and specialization in that rotation. Unfortunately, this is not clearly measurable with the current study design.

Early surgical exposure to rural practices may provide insights and change attitudes regarding rural practices. ${ }^{5}$ Future studies are needed to better understand the impact of the rural rotation on trainee attitudes and subsequent career decisions.

\section{Implications for Practice}

This study describes a surgically robust and unique rural rotation in an Otolaryngology Head and Neck Surgery residency program. By participating in rural residency rotations, trainees may better understand the nature of rural practice and be more apt to pursue a career in a rural community.

\section{Acknowledgements}

The authors would like to acknowledge Dr. Kari Nelson from the UNMC Graduate Medical Education Research and Education Program for her review of the manuscript and project guidance.

\section{References}

1 Crowson MG, Lin V. The Canadian OtolaryngologyHead and Neck Surgery Workforce in the Urban-Rural Continuum: Longitudinal Data from 2002 to 2013. Otolaryngol Head Neck Surg. 2018;158(1):127-134. doi:10.1177/0194599817733688

2 Cogbill TH, Bintz M. Rural General Surgery: A 38Year Experience with a Regional Network Established by an Integrated Health System in the Midwestern United States. J Am Coll Surg. 2017;225(1):115-123. doi:10.1016/j.jamcollsurg.2017.02.010

3 Feigin E, Ronen O. Making rural health care better: How to attract interns to rural hospital. Aust J Rural Health. 2019;27(2):139-145. doi:10.1111/ajr.12502

4 Mercier PJ, Skube SJ, Leonard SL, et al. Creating a Rural Surgery Track and a Review of Rural Surgery Training Programs. J Surg Educ. 2019;76(2):459-468. doi:10.1016/j.jsurg.2018.09.004

5 Deveney K, Deatherage M, Oehling D, Hunter J. Association between dedicated rural training year and the likelihood of becoming a general surgeon in a small town. JAMA Surg. 2013;148(9):817-821. doi:10.1001/jamasurg.2013.2681 